\title{
The Impact of the Storm-Induced SST Cooling on Hurricane Intensity
}

\author{
Tong ZHU ${ }^{1}$ and Da-Lin ZHANG*2 \\ ${ }^{1}$ CIRA/CSU at NOAA/NESDIS/ORA, Camp Springs, MD 20746, USA \\ ${ }^{2}$ Department of Meteorology, University of Maryland, College Park, MD 20742, USA
}

(Received 8 March 2005; revised 25 July 2005)

\begin{abstract}
The effects of storm-induced sea surface temperature (SST) cooling on hurricane intensity are investigated using a 5-day cloud-resolving simulation of Hurricane Bonnie (1998). Two sensitivity simulations are performed in which the storm-induced cooling is either ignored or shifted close to the modeled storm track. Results show marked sensitivity of the model-simulated storm intensity to the magnitude and relative position with respect to the hurricane track. It is shown that incorporation of the storm-induced cooling, with an average value of $1.3^{\circ} \mathrm{C}$, causes a $25-\mathrm{hPa}$ weakening of the hurricane, which is about 20 $\mathrm{hPa}$ per $1^{\circ} \mathrm{C}$ change in SST. Shifting the SST cooling close to the storm track generates the weakest storm, accounting for about $47 \%$ reduction in the storm intensity. It is found that the storm intensity changes are well correlated with the air-sea temperature difference. The results have important implications for the use of coupled hurricane-ocean models for numerical prediction of tropical cyclones.
\end{abstract}

Key words: SST feedback, hurricane intensity, numerical modeling

\section{Introduction}

It is well known that hurricane intensity is extremely sensitive to the magnitude of sea surface temperature (SST) (Emanuel, 1986, 1988; Holland, 1997). The SST effects can be categorized into (positive) direct and (negative) feedback effects. Clearly, the underlying warm ocean surface is an energy source for tropical cyclogenesis in the form of surface heat fluxes. This has been well demonstrated by many earlier observational and modeling studies (e.g., Riehl, 1950; Fisher, 1958; Ooyama, 1969). The maximum potential intensity (MPI) of tropical cyclones is also positively related to SST (Emanuel, 1988; Holland, 1997).

As tropical cyclones propagate under the influence of large-scale flows, the ocean surface wind stress on the right side of the track increases, leading to the entrainment of cold water from the underlying thermocline into the ocean mixed layer and then a decrease in SST. This storm-induced SST cooling phenomenon has been known since the 1960s (Leipper, 1967). Observational studies have showed that some hurricanes can generate an SST decrease up to $6^{\circ} \mathrm{C}$ (Bender et al., 1993). Sakaida et al. (1998) even reported a maximum of $9^{\circ} \mathrm{C}$ SST cooling after the passage of a typhoon. Many studies have indicated that the mag- nitude of the SST cooling is strongly dependent on the tropical cyclone intensity, translation speed and the oceanic mixed-layer depth. Price (1981) found that upwelling significantly enhances entrainment under slowly-moving hurricanes (i.e., $\leqslant 4 \mathrm{~m} \mathrm{~s}^{-1}$ ) and reduces the rightward bias of the SST response. In a coupled atmosphere-ocean modeling study, Bao et al. (2000) showed that the area of SST cooling decreases substantially when the oceanic mixed layer depth increases from 10 to $50 \mathrm{~m}$. In view of the important impact of SST on the storm intensity, it is highly desirable to take into account the SST feedback effects in hurricane models.

However, different conclusions have been reached on the storm feedback effects by previous coupled hurricane-ocean models. Chang and Anthes (1979) performed two sensitivity experiments in which SST was abruptly perturbed by $\pm 1^{\circ} \mathrm{C}$, respectively, after the control hurricane reached a steady state. They found that the central pressures in the two experiments were, respectively, $7 \mathrm{hPa}$ higher and $17 \mathrm{hPa}$ lower than the control value after a 24 -h integration. Sutyrin and Khain (1984) showed that the tropical cyclone intensity in a three-dimensional coupled model is weakened by $5-7 \mathrm{hPa}$. Using a simple axisymmetric coupled hurricane-ocean model, Schade and Emanuel (1999)

*E-mail: dalin@atmos.umd.edu 
demonstrated that the SST feedback effect could reduce the hurricane's intensity by more than $50 \%$. Bender and Ginis (2000) performed several real-data simulations with the Geophysical Fluid Dynamics Laboratory (GFDL) coupled hurricane model. Their results confirmed the previous conclusions from the idealized simulation studies that the storm-induced SST cooling could have a significant impact on the intensity of tropical cyclones. Specifically, the simulated Hurricane Gilbert (1988) deepens by $10 \mathrm{hPa}$ and $25 \mathrm{hPa}$, when the GFDL model is coupled and uncoupled with the ocean model, respectively. In contrast, another real-data simulation study of Hurricane Opal (1995) by Hong et al. (2000), using the coupled Naval Research Laboratory's atmospheric mesoscale model and the GFDL's modular ocean model, indicated that the hurricane-induced SST cooling effect is not significant when the storm encounters a warm-core ring in the Gulf of Mexico. The negative feedback effects only account for $5 \mathrm{hPa}$ in Opal's intensity while the total deepening of the storm is $73 \mathrm{hPa}$. They argued that this small feedback is due to the relatively large heat content of the warm-core ring. However, in another pair of sensitivity experiments without the warm-core ring of ocean water, the negative feedback is about $8 \mathrm{hPa}$ out of the total of $63-\mathrm{hPa}$ deepening, also indicating the small feedback effects. The above review reveals some disagreements among different studies or different coupled models about the impact of the storm-induced SST changes on tropical cyclone intensity.

It appears that the SST feedback effects depend not only on the treatments of the storm-induced vertical mixing in ocean models, but also the parameterization of surface fluxes in atmospheric models. An analysis of high-resolution measurements for Hurricane Gilbert (1988) reveals that the heat and mass budgets in the ocean mixed layer depend highly upon the mixing parameterization scheme used (Jacob et al., 2000). Braun and Tao (2000) showed the marked sensitivity of Hurricane Bob (1991) to several planetary boundary layer (PBL) schemes. In addition, obtaining an accurate SST feedback representation in hurricane models requires the incorporation of an ocean-wave model with realistic treatments of the wind-induced waves and the associated surface stress, which involves various complicated interactions between the wind-induced waves and the atmospheric and oceanic boundary layers.

The purposes of the present study are to quantify the impact of (1) the storm-induced SST cooling, and (2) the relative position of the SST cooling with respect to the storm track on the intensity of Hurricane Bonnie (1998) with the Pennsylvania State University-National Center for Atmospheric Research (PSU-NCAR) mesoscale model (i.e., MM5; Grell et al., 1995). The next section summarizes briefly the control simulation and describes the model design of the sensitivity simulations. Section 3 presents the sensitivity of the model-simulated storm intensity and track to different SST fields. Section 4 shows diagnosis of the processes leading to the changes in storm intensity. A summary and concluding remarks are given in the final section.

\section{Experiment design}

Zhu et al. (2004) showed a 5-day control simulation (CTL) of Hurricane Bonnie (1998) with a two-way interactive, triply nested-grid $(36 / 12 / 4 \mathrm{~km})$, cloudresolving version of the MM5 model. The model physics used for the finest 4-km resolution domain include the Tao-Simpson (1993) three-class ice [i.e., cloud ice $\left(q_{\mathrm{i}}\right)$, snow $\left(q_{\mathrm{s}}\right)$, and graupel $\left.\left(q_{\mathrm{g}}\right)\right]$ and cloud [i.e., cloud water $\left(q_{\mathrm{c}}\right)$, and rainwater $\left.\left(q_{\mathrm{r}}\right)\right]$ microphysics scheme, the Blackadar PBL parameterization (Zhang and Anthes, 1982) and a cloud-radiation interaction scheme (Dudhia, 1993). The cloud resolving scheme also allows for the generation of supercooled water.

The model initial conditions and lateral boundary conditions are obtained from the NCEP $2.5^{\circ} \times 2.5^{\circ}$ global analysis, which is then enhanced by rawinsondes and surface observations. The hurricane initial vortex is retrieved from the Advanced Microwave Sensing Unit-A (AMSU-A) measurements and several observed hurricane parameters (see Zhu et al., 2002).

In the control simulation, the SST field is updated daily using the Tropical Rainfall Measuring Mission (TRMM) Microwave Imager (TMI) level 1 standard product at $0.25^{\circ} \times 0.25^{\circ}$ latitude-longitude resolution (Chelton et al., 2000) to represent the storm-induced SST changes. Compared to the AVHRR SST, the TMI SST can be detected under most atmospheric conditions, because the microwave radiance can penetrate into cloudy layers. However, there were some observational gaps and missing data near the eyewall because of the contamination by heavy rainfall. The missing data were filled by a 3-day running mean of SST at each grid point where the data were missed, using the data up to the current model time. A 5-day averaged TMI SST field, given in Fig. 2 of Zhu et al. (2004), shows an area of more than $2{ }^{\circ} \mathrm{C}$ SST cooling along and on the right side of the observed track. Although it is highly desirable to use a coupled hurricaneocean-wave model to represent the storm-induced SST changes, particularly for operational models, our approach should produce smaller SST errors than those from a coupled ocean model. In fact, the 5-day control simulation reproduces reasonably well the track, intensity change and asymmetric inner-core structures of the storm, including a partial eyewall and an eyewall replacement cycle [see Zhu et al. (2004) for more detail]. 


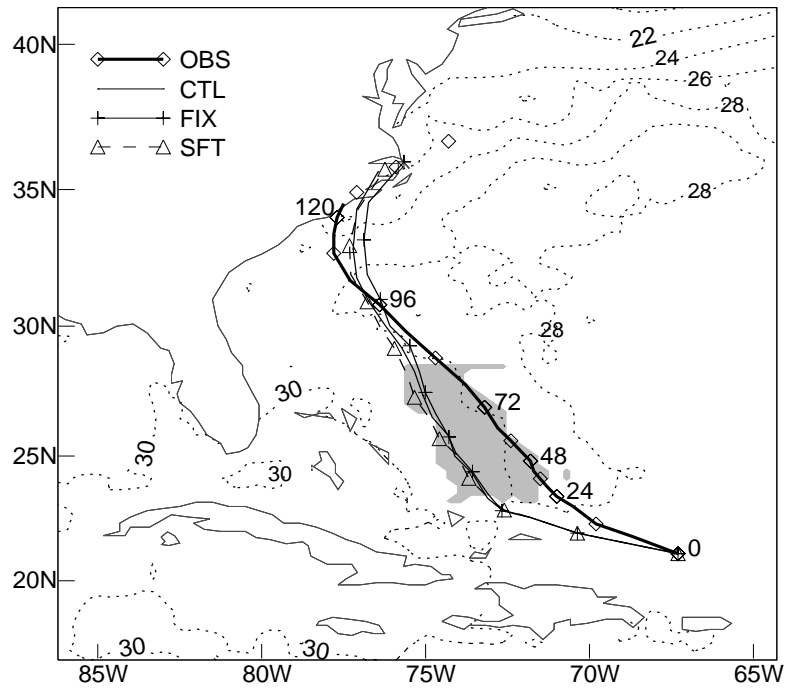

Fig. 1. Tracks of Bonnie from the best analysis (thick solid line) and three model simulations, superposed with the 5-day (22-27 August 1998) averaged SST (dotted) for the control experiment. The SST values less than $28^{\circ} \mathrm{C}$ used for the SFT experiment are shaded.

Despite the use of the observed SST field, the storm-induced cooling area is not compatible with the control-simulated track, namely, it is situated 100-250 $\mathrm{km}$ to the right due to the simulated track error in the first 72-h integration (see Fig. 1). This track error is caused by the model's failure in reproducing the weakening of a subtropical high centered over Bermuda. As a result, the control-simulated storm experiences warmer SST over the right semi-circle of the track than the observed during the first two days. To test the impact of positioning the storm-induced cooling close to the simulated track on the storm intensity, a sensitivity experiment is designed in which the area of SST that is colder than $28^{\circ} \mathrm{C}$ is systematically shifted westward by about $200 \mathrm{~km}$ during the first three days (Expt. SFT), while holding all the other parameters identical to the control simulation. As shown in Fig. 1, this shift makes the storm-induced cooling area (with SST between $26^{\circ} \mathrm{C}$ and $28^{\circ} \mathrm{C}$ ) close to the simulated track more like the observed relative position.

Another sensitivity simulation is performed in which the initial SST distribution is temporally fixed during the 5-day simulation (Expt. FIX). Because of the absence of the storm-induced cooling, the SST field at the model initial time is warmer than that in both the control and SFT simulations. This simulation should show mostly the net effects of the storminduced cooling on the storm intensity, as compared to the simulations of SFT and FIX, although there were some small SST variations associated with the largescale oceanic circulations. We are also motivated to conduct this sensitivity simulation because fixed SST has been often used in many of the previous hurricane modeling studies.

\section{Results}

In this section, we examine the sensitivity of the simulated track and intensity in the above two sensitivity simulations with respect to the control simulation (CTL). It is evident from Fig. 1 that the simulated tracks in Expts. SFT and FIX follow closely the control-simulated one, with a displacement difference of less than $50 \mathrm{~km}$ at the end of the 5 -day integrations. Thus, we may state that the hurricane track is not very sensitive to the storm-induced SST changes and their relative positions.

By comparison, the simulated hurricane intensity is extremely sensitive to the storm-induced cooling, as indicated by pronounced differences in the minimum sea-level pressure (MSLP) beyond 30-h integration (see Fig. 2a). Fixing the SST produces the deepest storm with an MSLP of $927 \mathrm{hPa}$ compared to the control-simulated $952 \mathrm{hPa}$, whereas shifting the SST generates the weakest deepening rate during the first 4-day simulation. While the SFT-simulated MSLP is relatively weak at $48 \mathrm{~h}$, it is closer to the best track analysis among all the simulations after $60 \mathrm{~h}$. Of significance is that positioning the cooling area at the righthand location leads to $12-16 \mathrm{hPa}$ weakening from the control simulated between the 48 -h and 96 -h integration. This indicates the important role of not only the storm-induced cooling but also its relative positioning in determining the hurricane intensity.

On average, the time series of maximum surface winds are similar in intensity change to those of MSLP, except for the fluctuations associated with instantaneous surface winds. As with the MSLP curve, pronounced differences in hurricane intensity from the control simulation begin to emerge after the first 36-42 $\mathrm{h}$ development stage, and they decrease as the simulated storms weaken. The final solutions are all merged to the basic-state solution as the storms diminish in intensity. In the absence of the storm-induced cooling (i.e., in Expt. FIX), the model produces the most intense surface wind, i.e., more than $10 \mathrm{~m} \mathrm{~s}^{-1}$ greater than the control-simulated value during the maintenance stage. In contrast, shifting the cooling area causes a marked weakening of surface winds, like the MSLP field. In general, the model-simulated MSLP and maximum surface wind should be slightly stronger than the observed because of the use of high grid resolution. In this regard, the control-simulated fields compare more favorably to the observed in spite of the positioning error in the storm-induced cooling. Nevertheless, positioning the storm-induced cooling close to the track shows significant improvements in MSLP 

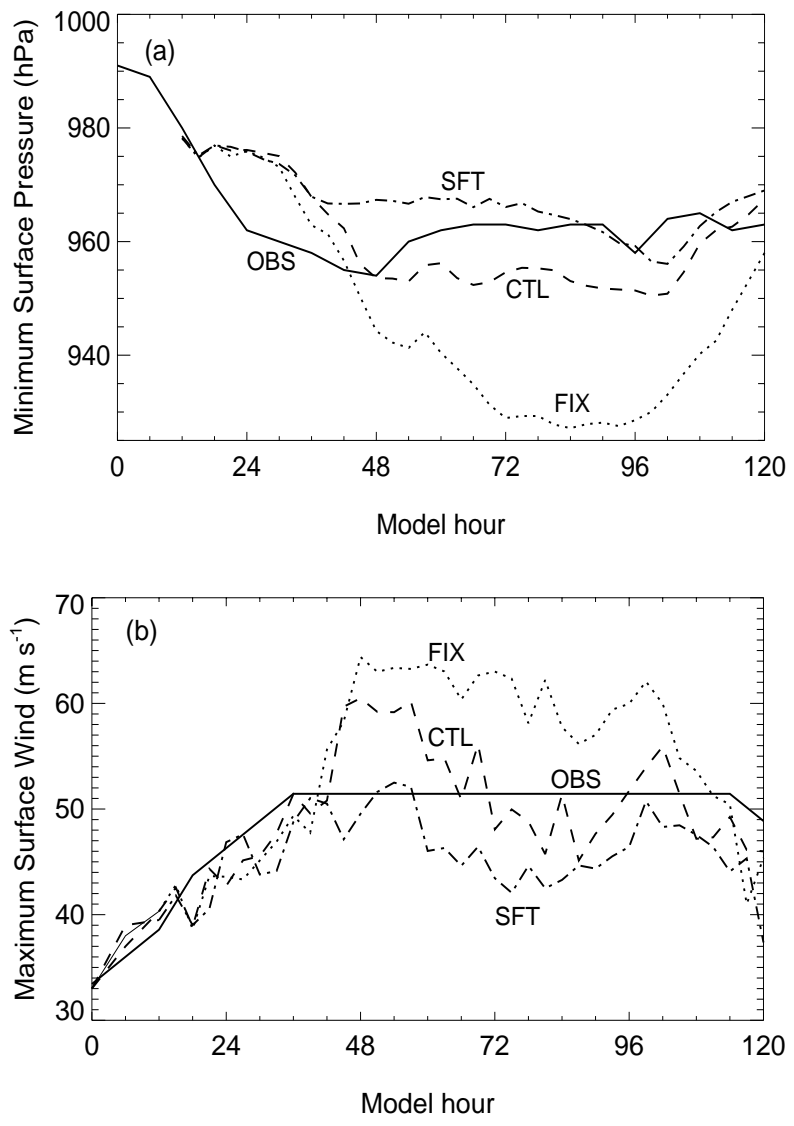

Fig. 2. Three-hourly time series of (a) the minimum sealevel pressure; (b) the maximum surface wind for the best analysis (OBS) and the three numerical experiments.

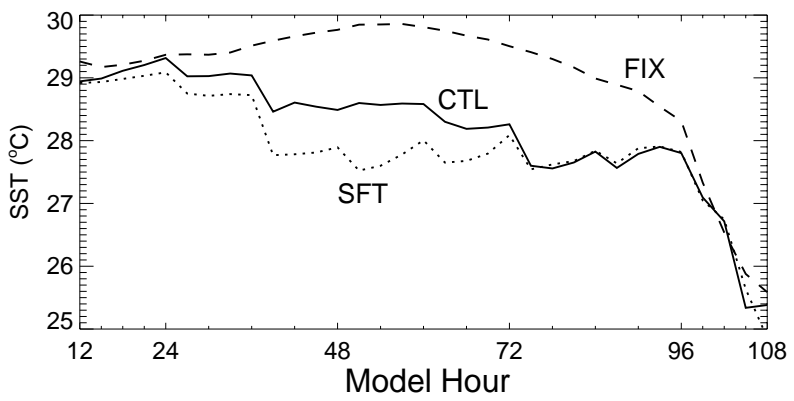

Fig. 3. Time series of the area-averaged $(400 \mathrm{~km} \times 400 \mathrm{~km})$ SST centered at the hurricane eye for the three numerical experiments.

and the maximum surface winds at later stages (cf. Figs. 2a, b).

To quantify the impact of the variable SSTs on the hurricane intensity, Fig. 3 shows the time series of the area-averaged SSTs following the storm's movement. One can see that the SST differences among the three simulations are small during the first $24 \mathrm{~h}$; Similarly this occurs for the SST fields after $96 \mathrm{~h}$ as the simulated storms move to cold water in the midlatitudes. On average, the storm-scale SST in Expt. FIX is about $1.3^{\circ} \mathrm{C}$ warmer than that in CTL during the 36-96-h period. Thus, the 25-hPa MSLP difference between FIX and CTL yields a 20-hPa deepening with a $1^{\circ} \mathrm{C}$ increase in SST during the 84 -h integration. Likewise, the MSLP difference between the SFT and CTL simulations gives an 18 -hPa deepening with an increase of $1^{\circ} \mathrm{C}$ SST from 36 to $72 \mathrm{~h}$. The deepening rate of $20 \mathrm{hPa}$ per degree warmth is near the lower limit of the MPI change range given by Holland (1997), but much higher than the $10 \mathrm{hPa}$ per degree MPI increase from Emanuel (1991), assuming typical hurricane environmental conditions. When the maximum intensity changes of the SFT (34 hPa) and FIX $(64 \mathrm{hPa})$ storms are compared, we find that including the storm-induced cooling can reduce the hurricane intensity by about $47 \%$, which is similar to the $50 \%$ intensity change shown by Schade and Emanuel (1999).

Because of the significant intensity changes, the incorporation of the storm-induced cooling also causes pronounced structural changes in surface winds and clouds/precipitation over the inner-core regions. Figure 4a shows that the analyzed surface wind is highly asymmetric with its peak value in excess of $85 \mathrm{kts}$ (or $44 \mathrm{~m} \mathrm{~s}^{-1}$ ) located to the northeast of the eye; the radius of maximum wind (RMW) is $51 \mathrm{n} \mathrm{mi} \mathrm{(or}$ $95 \mathrm{~km}$ ). Although all the simulations can reproduce the asymmetric flow patterns due to the influence of large-scale vertical shear, the magnitude of the surface wind speeds, the RMW and the cloud structures all differ from each other. Experiment FIX produces much stronger surface winds, greater than $60 \mathrm{~m} \mathrm{~s}^{-1}$, with an RMW of over $50 \mathrm{~km}$. The surface winds in Expt. CTL are also stronger but the RMW is smaller than the observed. On the other hand, Expt. SFT yields better the asymmetric flow structures with the maximum wind speed of $45 \mathrm{~m} \mathrm{~s}^{-1}$ and an RMW of 90 $\mathrm{km}$ at this time.

\section{Roles of the air-sea interaction}

The above results show that the hurricane intensity and structures are very sensitive to the storminduced SST cooling as well as to its relative position with respect to the storm track. The more realistic incorporation of the SST field in Expt. SFT appears to provide more reasonable simulation of the surface winds, and also asymmetric structures of clouds and precipitation at later stages. In this section, we examine how these differences are correlated to the air-sea interaction processes.

It is well known that in the air-sea interaction theory of Emanuel (1986), the surface sensible (SHF) and 
latent heat (LHF) fluxes play an important role in determining the hurricane intensity. They are computed in MM5 by

$$
\begin{aligned}
& \mathrm{SHF}=\rho c_{p} C_{\mathrm{h}}\left(\theta_{\mathrm{SEA}}-\theta_{\mathrm{a}}\right) \\
& \mathrm{LHF}=\rho L C_{q}\left(q_{\mathrm{s}}-q_{\mathrm{a}}\right),
\end{aligned}
$$

where $\theta_{\mathrm{SEA}}, \theta_{\mathrm{a}}, q_{\mathrm{a}}$, and $q_{\mathrm{s}}$ are the sea-level and surfacelayer potential temperature, surface specific humidity, and the saturation specific humidity at SST, respectively. The exchange coefficients for heat and moisture, $C_{\mathrm{h}}$ and $C_{q}$ in Eqs. (1) and (2), are given by

$$
\begin{aligned}
C_{\mathrm{h}} & =k u_{*}\left(\ln \frac{Z_{\mathrm{a}}}{Z_{T}}-\psi_{\mathrm{h}}\right)^{-1} \\
C_{q} & =k u_{*}\left[\ln \left(\frac{k u_{*} Z_{\mathrm{a}}}{K_{\mathrm{a}}}+\frac{Z_{\mathrm{a}}}{Z_{q}}\right)-\psi_{\mathrm{h}}\right]^{-1} \\
u_{*} & =\max \left(\frac{k V}{\ln \frac{Z_{\mathrm{a}}}{Z_{0}}-\psi_{\mathrm{m}}}, u_{* 0}\right)
\end{aligned}
$$

where $k$ is the von Kármán constant, $u_{*}$ is the frictional velocity, $u_{* 0}$ is a background value $\left(0.1 \mathrm{~m} \mathrm{~s}^{-1}\right.$ over land and zero over water), and $V$ is the wind speed at the lowest model level; $Z_{\mathrm{a}}$ is the height of the model lowest layer, $Z_{T}$ and $Z_{q}$ are the roughness lengths for heat and moisture given below. $K_{\mathrm{a}}$ is a background molecular diffusivity of $2.4 \times 10^{-5} \mathrm{~m}^{2} \mathrm{~s}^{-1}$. $\psi_{\mathrm{h}}$ and $\psi_{\mathrm{m}}$ are nondimensional stability parameters that are a function of the bulk Richardson number.

In this study, a modified version of the Blackadar PBL scheme is used to treat the roughness lengths over ocean for momentum, heat and moisture separately, in accordance with some recent studies (e.g., Garratt, 1992; Wang, 2001). The roughness length for momentum $z_{u}$ over ocean is given by

$$
z_{u}=a \frac{u_{*}^{2}}{g}+0.11 \frac{\mu}{u_{*}},
$$

as suggested by Smith (1988). The first term on the right hand side is the aerodynamic roughness of the ocean surface associated mainly with shorter surface waves, and is based on the formula of Charnock (1955). The Charnock constant is given as $a=0.016$ under moderate or strong wind conditions (Garratt, 1992). The second term on the right hand side is the roughness length for a smooth surface (Businger, 1982) that depends on the dynamic viscosity $(\mu)$ and the friction velocity $\left(u_{*}\right)$.

The roughness lengths for heat and moisture are based on Large and Pond (1982). A lower bound for either $z_{T}$ or $z_{q}$ is assumed so that the roughness length is not allowed to be less than the value corresponding to a smooth surface (Garratt, 1992).

$$
\begin{aligned}
& z_{T}=\max \left(4.9 \times 10^{-5}, 0.2 \frac{\mu}{u_{*}}\right), \\
& z_{q}=\max \left(1.3 \times 10^{-4}, 0.3 \frac{\mu}{u_{*}}\right),
\end{aligned}
$$

The above modifications tend to reduce the total upward energy flux and weaken the storm by about 5 $\mathrm{hPa}$ after 48-h into the control simulation of Hurricane Bonnie.

It is apparent from Eqs. (1)-(8) that the surface heat fluxes over ocean depend highly on the magnitude of surface winds, the air-sea temperature difference, roughness length and surface static stability. Zhang et al. (1999) demonstrated the strong correlation between surface wind speed $\left(V_{\mathrm{SFC}}\right)$ and $u_{*}$ whose isotachs are almost parallel to each other. Thus, in this study, we focus more on the time evolution of $V_{\mathrm{SFC}}$ and the air-sea temperature difference that is almost identical to $\theta_{\mathrm{SEA}}-\theta_{\mathrm{a}}$, in relation to the storm intensity. As shown in Fig. 5a, the area-averaged airsea temperature difference varies similarly among all three simulations, regardless of their different intensity changes. That is, the time series show a drop in the first 3-h model adjustment period, a nearly fixed value during the $3-39-\mathrm{h}$ period, an increase of more than $1{ }^{\circ} \mathrm{C}$ from 39 to $72 \mathrm{~h}$, and a subsequent reduction as the storms move to the cold water surfaces. Note that the air-sea temperature difference increases but with little change in SST during the 39-72-h period (cf. Figs. 3 and 5a). This indicates that the surface air temperature must have decreased, due mostly to the evaporation of precipitation in unsaturated convective downdrafts (Cione et al., 2000) and partly to the horizontal adiabatic cooling as the parcels are advected into lower pressures toward the eye (Liu et al., 1999). Of interest is that the time series of the areaaveraged surface winds and sea-level pressure, which differ from the instantaneous maximum surface wind and MSLP (cf. Figs. 5b, c and 2a, b), follow closely the general trend of the air-sea temperature difference in the first $72 \mathrm{~h}$ (cf. Figs. 5a, b, c). The latent heat release associated with the first 48-h deepening of the simulated storms must come from the moisture stored in the storm environments, since little moisture flux is "pumped" from the underlying ocean into the storm during this stage. As the storms deepen, ample moisture and sensible heat from the underlying ocean may lead to the positive feedback between latent heat release, surface pressure falls, amplifications of surface winds and increases of surface heat fluxes. This appears to explain the continued increase of the air-sea temperature difference and surface winds/sealevel pressure (Figs. 5a, b, c). After the first 72-h simulation, the air-sea temperature difference begins to decrease whereas the simulated storms do not start 
(a) Analysis

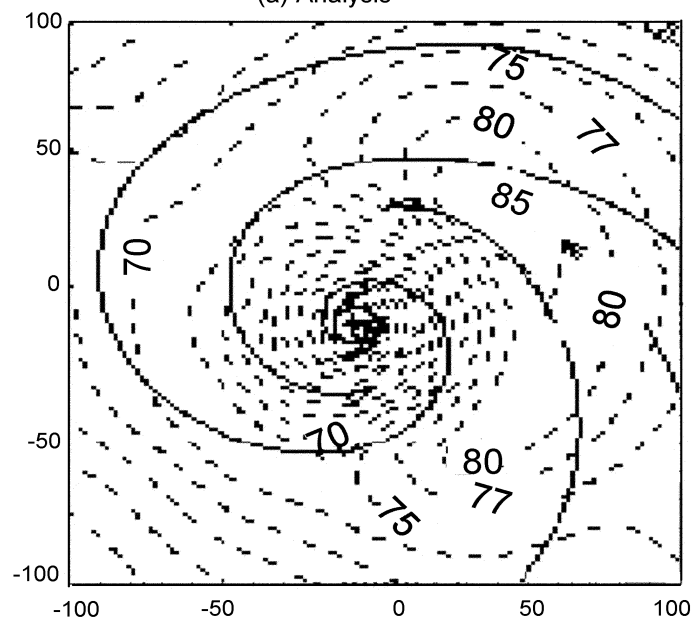

(c) FIX at $51 \mathrm{hr}$

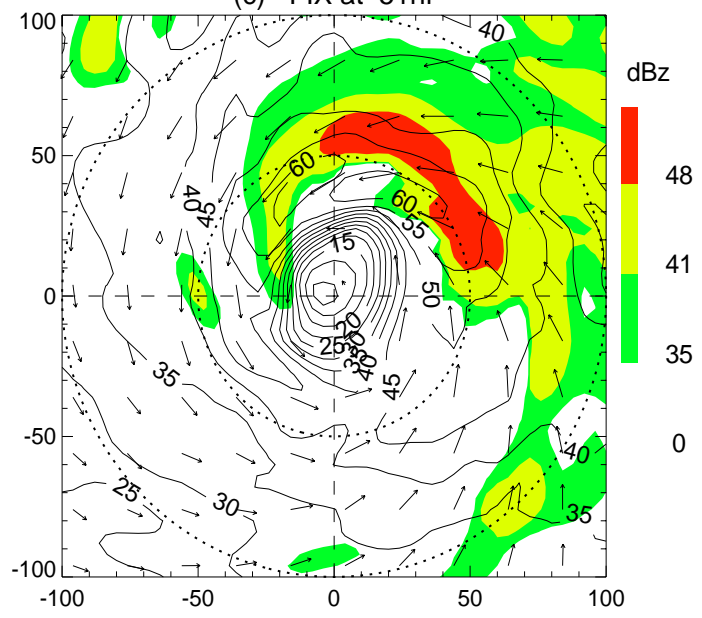

(b) CTL at $51 \mathrm{hr}$

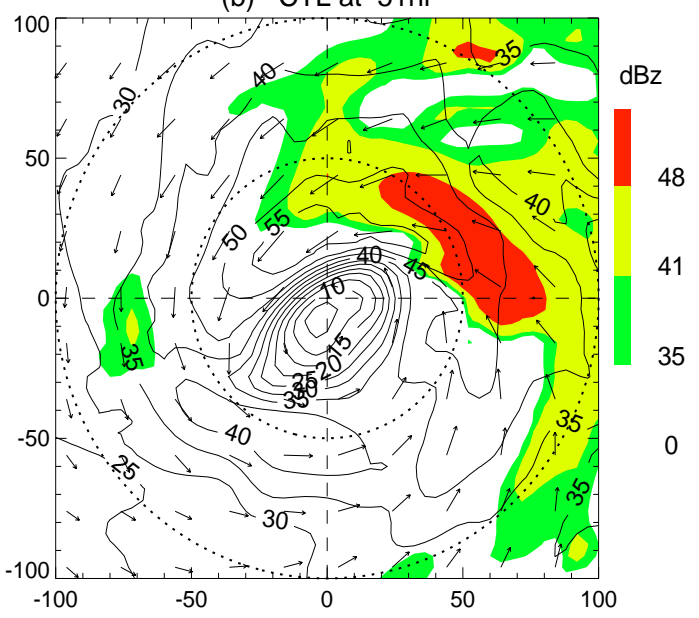

(d) SFT at $51 \mathrm{hr}$

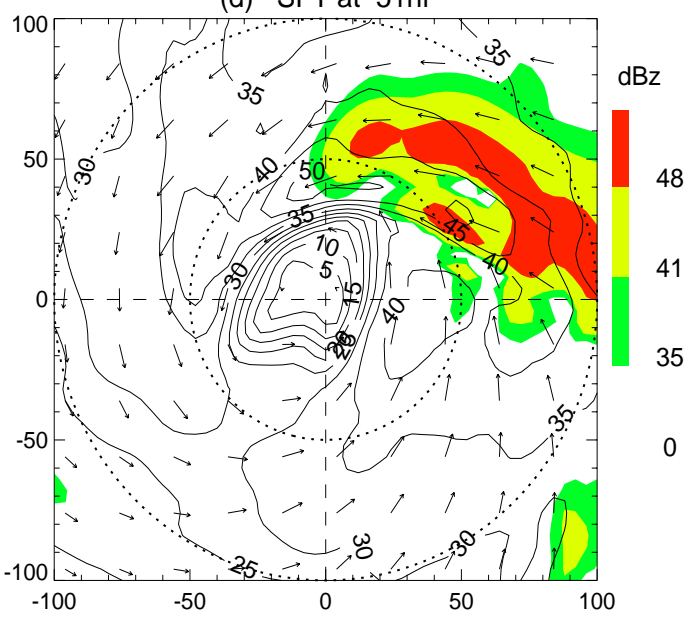

Fig. 4. (a) NOAA/Hurricane Research Division's surface wind (in kn) analysis for Hurricane Bonnie (1998) at 1830 UTC 24 August, with the maximum wind of $86 \mathrm{kn}$ at $51 \mathrm{n} \mathrm{mi} \mathrm{to} \mathrm{the} \mathrm{northeast} \mathrm{of} \mathrm{the} \mathrm{center;} \mathrm{and} \mathrm{the} \mathrm{surface}$ winds ( $\mathrm{m} \mathrm{s}^{-1}$, solid line) from 51-h simulations of (b) Expt. CTL; (c) Expt. FIX; and (d) Expt. SFT, superposed with the simulated radar reflectivities (shaded) at the surface.

their damping until $96 \mathrm{~h}$. This (24-h) delayed response to the air-sea temperature difference appears to be realistic because of the large inertial flow systems of the storms. In addition, the storms have moved to colder water surfaces after $96 \mathrm{~h}$, with SST values less than $27^{\circ} \mathrm{C}$ (Fig. 3), which are unfavorable for tropical cyclogenesis.

Of interest is that despite the continued intensity increase in both sea-level pressure and surface winds, the time series of the latent and sensible heat fluxes follow closely those of the air-sea temperature difference (cf. Figs. 5 and 6 ). This may be expected because the larger the air-sea temperature departures, the greater the surface sensible heat flux should be. It should be pointed out, however, that although the surface heat fluxes are more positively correlated to the air-sea temperature difference at the storm scale, the surface latent heat flux is more dependent on the magnitude of surface winds locally. In fact, the surface latent heat flux is 6 to 8 times in magnitude greater than the sensible heat flux (cf. Figs. 6a, b), indicating its more important role as an energy source for tropical cyclogenesis. Furthermore, the surface latent flux is also well correlated to the surface sensible heat flux, partly because the saturation specific humidity in Eq. (2) is simply a function of SST.

In Table 1, we summarize the area-averaged surface heat fluxes and SST at $60 \mathrm{~h}$ into the simulations. On average, the rates of the total surface heat fluxes are $267 \mathrm{~W} \mathrm{~m}^{-2}$ and $229 \mathrm{~W} \mathrm{~m}^{-2}$ per degree change, respectively, for Expts. SFT and FIX. These rates are in good agreement with the typical flux anomalies of 

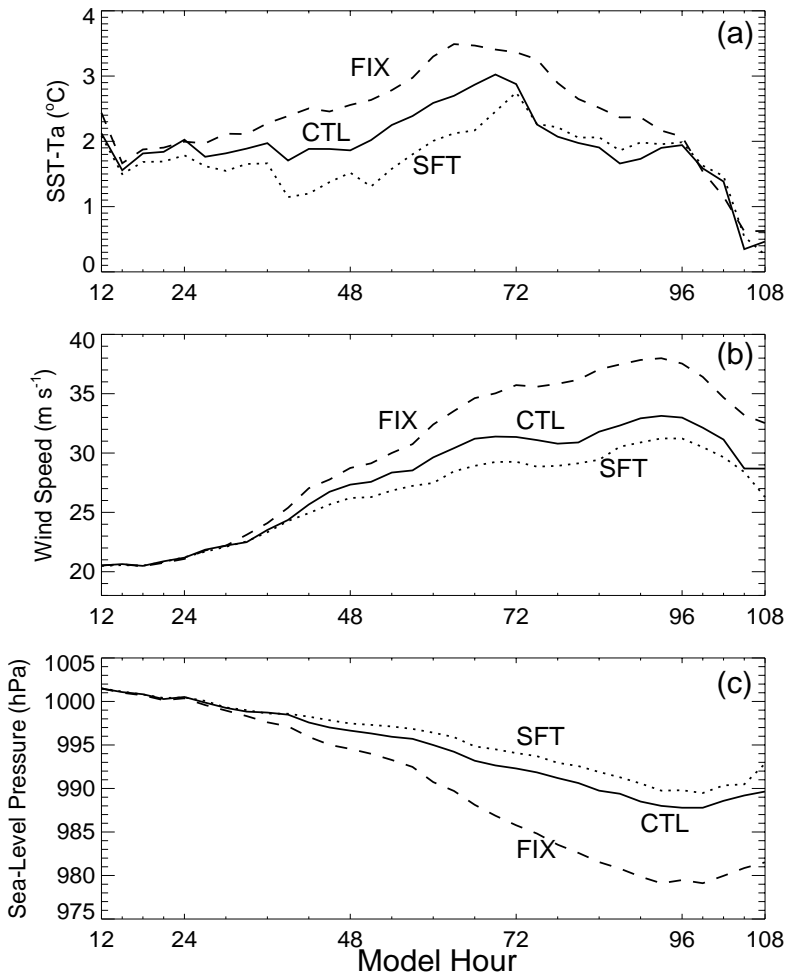

Fig. 5. Time series of the area-averaged (400 $\mathrm{km} \times 400$ km) (a) SST-Ta ; (b) surface wind speed; and (c) sea-level pressure.

Table 1. Area-averaged $(400 \mathrm{~km} \times 400 \mathrm{~km})$ surface fluxes of sensible and latent heat in relation to SST from all three 60-h simulations.

\begin{tabular}{ccccc}
\hline Experiment & $\begin{array}{c}\text { SHF } \\
\left(\mathrm{W} \mathrm{m}^{-2}\right)\end{array}$ & $\begin{array}{c}\text { LHF } \\
\left(\mathrm{W} \mathrm{m}^{-2}\right)\end{array}$ & Total flux & SST $\left({ }^{\circ} \mathrm{C}\right)$ \\
\hline CTL & 97 & 625 & 722 & 28.6 \\
FIX & 147 & 850 & 997 & 29.8 \\
SFT & 62 & 500 & 562 & 28.0 \\
\hline
\end{tabular}

$50 \mathrm{~W} \mathrm{~m}^{-2}$ with $0.2^{\circ} \mathrm{C}$ SST changes found by Cayan (1992) in an observational study. This indicates that Eqs. (1)-(5) used for the present study can provide a reasonable magnitude of surface heat fluxes associated with the air-sea temperature differences.

\section{Summary and conclusions}

In this study, the effects of storm-induced SST cooling on tropical cyclone intensity are investigated using 5-day simulations of Hurricane Bonnie (1998) with the MM5 model. The storm-induced cooling is introduced by updating daily the TMI SST satellite data. Two 5-day sensitivity simulations are performed by (1) shifting the observed SST cooling close to the simulated storm track, and (2) fixing the SST field at
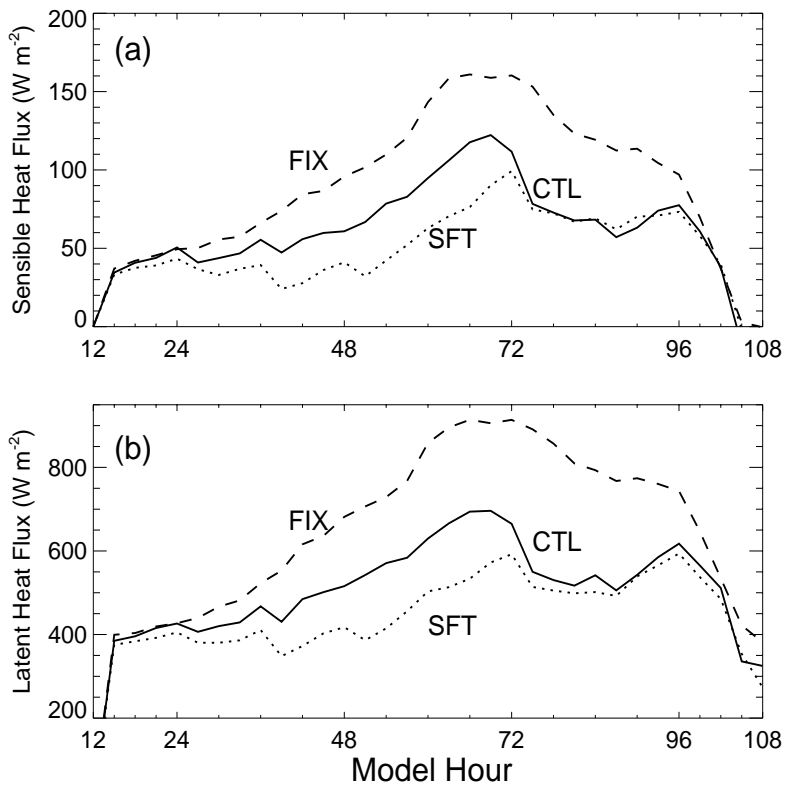

Fig. 6. Time series of the area-averaged $(400 \mathrm{~km} \times 400 \mathrm{~km})$ (a) surface sensible heat flux; and (b) surface latent heat flux.

the model initial time so that the storm-induced cooling is ignored.

It is found that the hurricane intensity is very sensitive to the storm-induced SST cooling, but the track is not. In the absence of the SST cooling, the model produces the strongest hurricane, with a value $25 \mathrm{hPa}$ deeper in MSLP than in the control simulation. Shifting the SST cooling close to the storm track generates the weakest storm because of the colder SST underneath the inner-core region. Results show that the deepening rate without the storm-induced cooling is about $18-20 \mathrm{hPa}$ for a $1^{\circ} \mathrm{C}$ increase in SST. When the storm-induced SST cooling is properly incorporated, the maximum hurricane intensity can be reduced by about $47 \%$ from the no-SST-cooling simulation. These results are quantitatively similar to those obtained by some of the previous coupled modeling studies.

Diagnoses of the sensitivity simulations reveal that the air-sea temperature difference is well correlated to the area-averaged surface sensible and latent heat fluxes, as well as to the averaged surface winds. Given the SST field, the cold surface air temperature in the inner-core region appears to determine the magnitude of the surface heat fluxes, and this cold air temperature has been hypothesized to result mostly from the evaporation of precipitation particles from the eyewall, and partly from the radially inward adiabatic cooling. The surface latent heat flux makes much more significant contributions to the total energy source of the storm.

In conclusion, we may state that the storm-induced SST cooling, in terms of its magnitude and relative 
position to the storm track, plays an important role in determining the hurricane intensity. A realistically coupled hurricane-ocean model should be used for operational hurricane forecasts beyond 2 days. In view of the important impact of surface heat fluxes on the hurricane intensity, it is also highly desirable to have a wind-driven wave model coupled with the hurricane and ocean models. This would provide more realistic representations of the wave-induced roughness lengths and the magnitude and distribution of the surface heat fluxes, thereby leading to more reasonable prediction of hurricane intensity.

Acknowledgments. The authors wish to thank Dr. Fuzhong Weng for his interest and support of this research. The work was supported by NASA Grants NAG-510746, NSF Grants ATM-0342363, and ONR Grant N000140210402, and CIRA/Colorado State University.

\section{REFERENCES}

Bao, J.-W., J. M. Wilczak, J.-K. Choi, and L. H. Kantha, 2000: Numerical simulations of air-sea interaction under high wind conditions using a coupled model: A study of hurricane development. Mon. Wea. Rev., 128, 2190-2210.

Bender, M. A., I. Ginis, and Y. Kurihara, 1993: Numerical simulations of tropical cyclone-ocean interaction with a high resolution coupled model. J. Geophys. Res., 98, 23245-23263.

Bender, M. A., and I. Ginis, 2000: Real-case simulations of hurricane-ocean interaction using a high-resolution coupled model: Effects on hurricane intensity. Mon. Wea. Rev., 128, 917-946.

Braun, S. A., and W.-K. Tao, 2000: Sensitivity of highresolution simulations of Hurricane Bob (1991) to planetary boundary layer parameterizations. Mon. Wea. Rev., 128, 3941-3961.

Businger, J. A., 1982: Equations and concepts. Atmospheric Turbulence and Air Pollution Modeling, F. T. M. Nieuwstadt and H. van Dop, Eds., Reidel, Dordrecht, 1-36.

Cayan, D. R., 1992: Latent and sensible heat flux anomalies over the northern oceans: Driving the sea surface temperature. J. Phys. Oceanogr., 22, 859-881.

Chang, S. W., and R. A. Anthes, 1979: The mutual response of the tropical cyclone and the ocean. J. Phys. Oceanogr., 9, 128-135.

Charnock, H., 1955: Wind stress on a water surface. Quart. J. Roy. Meteor. Soc., 81, 639-940.

Chelton, D. B., F. J. Wentz, C. L. Gentemann, R. A. de Szoeke, and M. G. Schlax, 2000: Satellite microwave SST observations of transequatorial tropical instability waves. Geophys. Res. Lett., 27, 1239-1242.

Cione, J. J., P. G. Black, and S. H. Houston, 2000: Surface observations in the hurricane environment. Mon. Wea. Rev., 128, 1550-1561.
Dudhia, J., 1993: A nonhydrostatic version of the Penn State-NCAR mesoscale model: Validation tests and simulation of an Atlantic cyclone and cold front. Mon. Wea. Rev., 121, 1493-1513.

Emanuel, K. A., 1986: An air-sea interaction theory for tropical cyclones. Part I: Steady-state maintenance. J. Atmos. Sci., 43, 585-604.

Emanuel, K. A., 1988 : Toward a general theory of hurricanes. American Scientist, 76, 371-379.

Emanuel, K. A., 1991: The theory of hurricanes. Annual Review of Fluid Mechanics, 23, 179-196.

Fisher, E. L., 1958: Hurricane and the sea surface temperature field. J. Meteor., 15, 328-333.

Garratt, J. R., 1992: The Atmospheric Boundary Layer. Cambridge University Press, 316pp.

Grell, G. A., J. Dudhia, and D. R. Stauffer, 1995: A description of the Fifth Generation Penn State/NCAR Mesoscale Model (MM5). NCAR Tech Note NCAR/TN-398+STR, 138pp. [Available from NCAR Publications Office, P. O. Box 3000, Boulder, CO 80307-3000.]

Holland, G. J., 1997: Maximum potential intensity of tropical cyclones. J. Atmos. Sci., 54, 2519-2541.

Hong, X., S. W. Chang, S. Raman, L. K. Shay, and R. Hodur, 2000: The interaction between Hurricane Opal (1995) and a warm core ring in the Gulf of Mexico. Mon. Wea. Rev., 128, 1347-1365.

Jacob, S. D., L. K. Shay, A. J. Mariano, and P. G. Black, 2000: The 3-D oceanic mixed layer response to Hurricane Gilbert. J. Phys. Oceanogr., 30, 1407-1429.

Large, W. G., and S. Pond, 1982: Sensible and latent heat flux measurements over the ocean. J. Phys. Oceanogr., 12, 464-482.

Leipper, D., 1967: Observed ocean conditions and Hurricane Hilda, 1964. J. Atmos. Sci., 24, 182-196.

Liu, Y., D.-L. Zhang and M.K. Yau, 1999: A multiscale numerical study of Hurricane Andrew (1992). Part II: Kinematics and inner-core structures. Mon. Wea. Rev., 127, 2597-2616.

Ooyama, K., 1969: Numerical simulation of the life cycle of tropical cyclones. J. Atmos. Sci., 26, 3-40.

Price, J. F., 1981: Upper ocean response to a hurricane. J. Phys. Oceanogr., 11, 153-175.

Riehl, H., 1950: A model for hurricane formation. J. Appl. Phys., 21, 917-925.

Sakaida, F., H. Kawamura, and Y. Toba, 1998: Sea surface cooling caused by typhoons in the Tohuku area in August 1989. J. Geophys. Res., 103(C1), 1053-1065.

Schade, L. R., and K. A. Emanuel, 1999: The ocean's effect on the intensity of tropical cyclones: Results from a simple coupled atmospheric-ocean model. J. Atmos. Sci., 56, 642-651.

Smith, S. D., 1988: Coefficients for sea surface wind stress, heat flux, and wind profiles as a function of wind speed and temperature. J. Geophys. Res., 93, 15467-15472.

Sutyrin, G. G., and A. P. Khain, 1984: Effect of the oceanatmosphere interaction on the intensity of a moving tropical cyclone. Atmospheric and Oceanic Physics, 20, 787-794. 
Tao, W.-K., and J. Simpson, 1993: The Goddard cumulus ensemble model. Part I: Model description. Terr. Atmos. Oceanic Sci., 4, 35-72.

Wang, Y., 2001: An explicit simulation of tropical cyclones with a triply nested movable mesh primitive equation model-TCM3. Part I: Description of the model and control experiment. Mon. Wea. Rev., 129, 1270-1294.

Zhang, D., and R. A. Anthes, 1982: A high-resolution model of the planetary boundary layer-Sensitivity tests and comparisons with SESAME-79 data. J. Appl. Meteor., 21, 1594-1609.
Zhang, D.-L., Y. Liu, and M. K. Yau, 1999: Surface winds at landfall of Hurricane Andrew (1992) - A reply. Mon. Wea. Rev., 127, 1711-1721.

Zhu, Tong, D.-L. Zhang, and F. Weng, 2002: Impact of the advanced microwave sounding unit measurements on hurricane prediction. Mon. Wea. Rev., 130, 24162432.

Zhu, Tong, D.-L. Zhang, and F. Weng, 2004: Numerical simulation of Hurricane Bonnie (1998). Part I: Eyewall evolution and intensity changes. Mon. Wea. Rev., 132, 225-241. 